\title{
Exploring Ways to Support Preservice Teachers' Use of UDL in Planning and Instruction
}

\author{
K. Alisa Lowrey \\ University of Southern Mississippi \\ Audra Classen \\ University of Southern Mississippi \\ Anne Sylvest \\ University of Southern Mississippi
}

\begin{abstract}
There is limited research documenting current efforts to support preservice teachers to use the universal design for learning (UDL) framework in authentic teaching experiences. To increase knowledge on the effects of preparing preservice teachers to incorporate the UDL framework, researchers examined the effects a UDL professional development seminar that was delivered during the student teaching phase had on eight teacher candidates during their K-12 placement. Using a concurrent triangulation mixed-method design, researchers examined lesson plans, video footage of teaching, teacher candidate reflections on their teaching sample, and university supervisor measures of the same sample before and after the UDL seminar. Findings are shared as well as recommendations for future practice.
\end{abstract}

Keywords: universal design for learning, preservice teachers, professional development

\section{Introduction}

The universal design for learning (UDL) is an instructional framework used to impact the goals, materials, methods, and assessments used by educators in the design and implementation of instruction (Hall, Meyer, \& Rose, 2012). Based on neuroscience and supported by research-based instructional practices, teachers should consider the framework, which consists of three principles, nine guidelines, and 31 checkpoints when designing curriculum and instruction. Instruction planned through the UDL framework intentionally allows for learner variability and embraces flexibility in the engagement of students, representation of content, and the learner's expression of knowledge. Since the initial Rose and Meyer (2002) publication, Teaching Every Student in the Digital Age, the UDL framework has purposed to make learning more accessible to all learners, including those with and without disabilities.

The Higher Education Opportunity Act (2008), Every Student Succeeds Act (2015), and the National Education Technology Plan (U.S. Department of Education, Office of Educational Technology, 2016) all recommend using the UDL framework. Heralded as a framework that can increase inclusive opportunities while simultaneously lessening the number of accommodations and modifications necessary for students with disabilities (Sailor \& McCart, 2014), the UDL framework has demonstrated positive learning gains for students with disabilities when applied in inclusive classrooms (Browder, Mims, Spooner, Ahlgrim-Delzell, \& Lee, 2009; Coyne, Pisha, Dalton, Zeph, \& Smith, 2012; Dymond et al., 2006; Kortering, McClannon, \& Baziel, 2008; Lieber, Horn, Palmer, \& Fleming, 2008). Although included in policy and legislation as an important educational framework for implementation in instructional design, to date, no research-based preservice professional 
development model is available to support teacher candidates (TCs) to adequately understand, implement, and evaluate the UDL framework in authentic school settings.

Teachers can have a significant impact on students' learning (Waitoller \& Artiles, 2013). Teacher effect is larger than the school effect on student learning (Nye, Konstantopoulos, \& Hedges, 2004). The Organization for Economic Cooperation and Development (2005) has identified teacher quality as the most important variable affecting student achievement. A critical element of any school system is the "capacity to nurture and develop teachers who have the understandings, skills, critical sensibilities, and contextual awareness to provide quality educational access, participation, and outcomes for all students" (Waitoller \& Artiles, 2013, p. 320). The UDL framework is directly tied to effective curriculum design and instruction, appropriate for all content areas, and leads to improved outcomes for all students (Center for Applied Special Technology [CAST], 2011). Preparing TCs to implement the UDL framework promotes access to and progress in the general education curriculum and may lead to increased outcomes for their future students (Holdheide \& Reschley, 2008).

\section{UDL in Preservice Teaching}

Limited research exists documenting current efforts to teach preservice teachers to use the UDL framework. Several studies seem to include UDL as a component (Allday, Neilsen-Gatti, \& Hudson, 2013; Marino, Sameshima, \& Beecher, 2009; Van Laarhoven, Munk, Chandler, Zurita, \& Lynch, 2012) but not the applied intervention or focus. Most studies focusing on UDL are descriptive (Rao, Ok, \& Bryant, 2014). However, selections have guided implementation of the UDL framework in preservice teacher training and education.

Israel, Ribuffo, and Smith (2014) offered recommendations for preservice teacher preparation content coursework. Key to their recommendations was that TCs must have a basic understanding of the UDL framework as a prerequisite to UDL implementation. Israel and colleagues made specific content and resource suggestions for integrating the UDL framework in preservice teacher education programs. Furthermore, they stressed it was critical to focus on flexibility, student diversity (i.e., variability), and the upfront identification of barriers to the learning experience. This focus differs from most curricular design instruction for preservice TCs. After a general understanding of the UDL framework has been achieved, Israel et al. recommended requiring TCs to plan instruction using the UDL framework. Specifically, they detail existing tools such as Planning for All Learners (Meo, 2008) or larger concepts such as the Critical Elements of UDL offered by the Universal Design for Learning-Implementation and Research Network (2011). Israel and colleagues (2014) also offered suggestions for activities related to designing and evaluating curriculum, instruction, student progress, use of technology, and assessment.

Using these recommendations, Scott, Thoma, Puglia, Temple, and d'Aguilar (2017) created and distributed a 23-question survey. Forty-eight Special Education Personnel Preparation programs from across the United States responded. Results of this survey indicated all responding programs included some form of preparation on at least one of the three UDL principles in their teacher preparation coursework. Respondents categorized this inclusion of principles ranging from a great extent to very little. Only $25 \%$ of the programs were implemented at the level of great extent. As the authors noted, this could reflect a wide range of variability in the instruction and comprehension of the basic components of the UDL framework. Additionally, the authors noted the lack of opportunity to practice in natural education settings as a limitation.

Two studies applied UDL framework instruction as an independent variable followed by measuring the effects of that instruction on preservice teacher planning. Spooner, Baker, Harris, AhlgrimDelzell, and Browder (2007) evaluated the planning of 72 preservice teachers in a graduate and undergraduate program after presenting a 1-hr class on UDL. TCs were taught to write lesson plans 
applying the principles of UDL. Researchers developed a rubric to measure the inclusion of UDL principles. Spooner and colleagues evaluated lesson plans using their established rubric. Results indicated this simple intervention positively impacted TCs' ability to plan for meeting the needs of all learners using the UDL framework.

Courey, Tappe, Siker, and LePage (2013) integrated UDL into their teacher preparation education program through the implementation of a $3-\mathrm{hr}$ module focusing on flexible materials, techniques, and instructional delivery strategies. Forty-five graduate students participated in the study. Researchers used the rubric developed by Spooner et al. (2007) to measure lesson plans. Results indicated improvement in the number of UDL principles included in the design of their lesson plans. More importantly, during the maintenance phase, candidates continued to implement the principles of UDL in their planning, therefore making the brief UDL instruction impactful over time. However, one of the limitations pointed out in this study was that researchers had no way of knowing if the components listed on the lesson plans were incorporated into the students' actual teaching.

In a description of their program, Evans, Williams, King, and Metcalf (2010) provided details of their efforts to redesign their teacher preparation program to integrate the principles of UDL. Researchers emphasized UDL in a course designed to teach lesson planning. They used graphic organizers, thinkalouds, pyramid planning, and videoed lessons to facilitate students' understanding and application of multiple means of representation, engagement, and instruction across their unit and lesson plans. Additionally, Evans and colleagues supported practice teaching of at least one student developed lesson in authentic K-12 settings or simulated settings. Their study describes their experiences throughout their program redesign.

In examining the student teaching experience, Spooner et al. (2007), Courey et al. (2013), and Evans et al. (2010) used a sequence of tools as preexisting sets in their present evaluation of TCs: lesson planning, observed instruction, and TC reflection. While the aforementioned studies examined the implementation of the UDL framework in lesson planning, no study was identified examining the implementation of the UDL framework in lesson planning, observed teaching, and written reflections of TCs. The purpose of this study was to determine whether or not a UDL professional development seminar, delivered during student teaching, would impact the way a TC planned, implemented, and reflected on a lesson. To extend the data on preservice teaching, researchers examined lesson plans, video footage of teaching, TC reflections on their teaching sample, and university supervisor measures of the same sample.

\section{Method}

This study examines the impact of a UDL seminar on lesson planning, implementation, and reflection completed by preservice teachers during their student teaching. This study employs a concurrent triangulation mixed-method design (Creswell, Plano Clark, Gutman, \& Hanson, 2003). Researchers collected qualitative and quantitative data in two phases of the TCs' student teaching experience. Data were analyzed separately and then compared. This method was used to crossvalidate and strengthen the study's findings. Mixed-method designs use both an inductive and deductive approach. Multiple data sources were collected at the same time and were analyzed using both quantitative and qualitative procedures (Creswell \& Garret, 2008). This study was approved by the institutional review board. Two researchers in the field of special education working at a Carnegie-designated "research highest" university in the south conducted the study.

\section{Participants}

Study participants were TCs placed in their final student teaching course prior to graduation. At the University of Southern Mississippi, students are placed in two 8-week student teaching experiences. 
As part of their regular schedule, a week of professional development was planned between TCs' first and second 8-week placements. The education field experience (EFE) coordinator dedicated 1 of these days to a UDL professional development seminar. Because the researchers integrated the pilot study into the existing scheduled seminars and student teaching requirements, the only consent required of TCs was to have their data included as part of the research findings. TCs signed a consent form indicating their permission to have their first placement traditional lesson plan components (traditional lesson template, video, reflection) and their second placement UDL lesson plan components (UDL lesson template, video, reflection) submitted as data. TCs not wishing to share their data declined inclusion by checking a box on the form. Because the EFE coordinator agreed that learning the UDL framework was an important professional development, all other TCs were still required to attend the seminar. A total of eight TCs participated by submitting all data components for measurement (two lesson plans, two videos, and two reflections) from their first and second experience. Table 1 provides a summary of specific participant demographic information. Seven TCs (elementary and physical education majors) completed the first and second student teaching experiences in one elementary school while one TC (a special education major) taught in an elementary setting for the first experience and a secondary setting for the second experience. Only one TC (i.e., the special education major) had been exposed to the principles of UDL in the teacher education coursework before the preservice seminar.

\begin{tabular}{ll}
\multicolumn{2}{l}{ Table 1. Demographics of Teacher Candidate Participants $(\mathrm{N}=8)$} \\
\hline Demographic & $\boldsymbol{n}$ \\
\hline Gender & 7 \\
$\quad$ Female & 1 \\
$\quad$ Male & \\
Race & 2 \\
$\quad$ African American & 6 \\
$\quad$ Caucasian & \\
Teaching setting & 7 \\
$\quad$ Elementary & 1 \\
$\quad$ Elementary and secondary & \\
Major & 1 \\
$\quad$ Special education & 6 \\
$\quad$ Elementary education & 1 \\
Physical education &
\end{tabular}

\section{Procedures}

Prior to the start of the semester, researchers planned the UDL seminar and obtained institutional review board approval. Procedures existing prior to this study required TCs to submit two traditional lesson plans, two lesson videos, and two lesson reflections as assessments (traditional lesson plans are defined as those meeting the acceptance criteria of the university teacher preparation program, see Appendix A). In response to all student teachers' exposure to UDL lesson planning and to assist with the study, EFE required TCs to submit a traditional lesson plan, video, and reflection during the first 8-week student teaching experience followed by a UDL-designed lesson plan, video, and reflection during their second 8-week student teaching experience. Due to this change, researchers invited all TCs and university supervisors to a brief (approximately 30-min) UDL introductory presentation at the beginning of the semester. The purpose of this introductory presentation was to introduce the UDL principles and conduct informed consent procedures.

\section{UDL Seminar Plan}

Following the completion of student teachers' first 8-week placement, researchers conducted a UDL seminar to increase TCs' knowledge of the UDL framework. This seminar lasted $6 \mathrm{hr}$. One hundred 
nine TCs and three university supervisors attended. Using the UDL framework throughout, the researchers introduced the concepts of learner variability and the identification of barriers in the learning environment; intentionally modeled ways to use multiple means of engagement, representation, and action/expression; and provided resources on UDL. Researchers guided TCs through each principle in an instructional context and had them focus on the guidelines and checkpoints as they applied to each principle. Researchers integrated these UDL principles throughout the seminar, and examples can be found in Table 2. Investigators also presented resources for additional help with UDL. Researchers embedded examples of learner variability and barriers to instruction found in the general education classroom throughout the seminar. As depicted in Table 2, the researcher presented content by modeling and providing opportunities for seminar attendees to experience each UDL principle.

Table 2. Universal Design for Learning (UDL) Seminar Design: Principles, Examples, and Resources

\begin{tabular}{llc}
\hline UDL Principle & Examples & Resources Used \\
\hline Engagement & Used round-table learning structure to & https://www.polleverywhere.com \\
& generate ideas for increasing engagement & \\
& Created a poll for participants & \\
& Used group discussion to generate ideas or & \\
& summarize information & \\
Representation & Used Microsoft PowerPoint presentation & http://www.cast.org/our-work/about- \\
& format & udl.html\#.VbZMrrNVhBc \\
& Used Wizard of $O z$ movie clip & https://www.youtube.com/watch?v=bD \\
& Compared characters to UDL principles: & vKnY0g6e4 \\
& Tin Man = engagement & http://static1.squarespace.com/static/5 \\
& Scarecrow = representation & 03427d124ac5fb46aa4494b/t/54adfd \\
& Lion = action/expression & dde4b07672716dff15/142068886184 \\
& Showed UDL framework videos & IRN_Blueprint_V1.pdf \\
& Provided UDL blueprint & http://www.cast.org/our-work/about- \\
& Provided critical elements handouts & udl.html\#.WG3w0FUrLIU \\
& & http://udl-irn.org/critical-elements/ \\
& & http://lessonbuilder.cast.org/ \\
Action/expression & \\
& Peers rated ideas generated by group & \\
& Participants Tweeted their takeaways from & \\
& critical elements discussion & \\
& Participants created a mini-UDL lesson &
\end{tabular}

Researchers then presented the upcoming assignment to students. A CAST UDL lesson plan template (found in Appendix B) was used for the second required lesson plan submission. This UDL lesson plan template was not modified. The UDL lesson plan template was introduced to all seminar attendees since it was suggested for their second lesson plan submission. The researchers led TCs to compare and contrast a traditional lesson plan and the UDL lesson plan during the seminar. In addition, the UDL model lesson plans were embedded throughout seminar activities. The seminar concluded by having TCs construct a sample lesson plan with peers teaching in the same grade level or content area.

\section{Data Collection Procedures}

For the purpose of measuring TC implementation, participants concurrently submitted multiple data sources (i.e., two lesson plans, two videos, and two reflections) as requirements of their student teaching experiences. TCs submitted all data components to the online, password-protected, document storage system used by the university, TK20. Researchers did not have access until the 
semester was completed and grades were posted. Following the end of the semester, researchers sent the TK20 administrator a list of consenting TCs. The TK20 administrator removed identifiable information, assigned each participant a code, and put all of their data in a file. The TK20 administrator shared each TC's file with the researchers as a blinded set of documents through the password-protected Microsoft Office 365 OneDrive.

\section{Traditional Lesson Plan Data}

During the first 8-week student teaching experience, TCs submitted a traditional lesson plan, video recording of the lesson implementation, and a lesson reflection. The traditional lesson plan (Appendix A) consisted of general demographic information, standards, learning objectives, assessment, differentiation/accommodations, anticipatory set, instructional procedures, instructional strategies, closure, and materials. This template of planning had been used by EFE for 19 years. TCs were required to complete the following steps for Phase 1 assignments:

- $\quad$ Plan a lesson using the traditional template.

- Video record the planned lesson being instructed.

- $\quad$ Edit the video recording to 10 min focusing on the introduction, instruction, and closure of the lesson (this requirement was necessary due to the storage capacity of TK20).

- $\quad$ Self-evaluate using the In-Class Evaluation.

- Write a two-page reflective analysis of their teaching.

\section{UDL Lesson Plan Data}

During the second 8-week session of their student teaching experience, the exact same procedure was followed with the exception that the traditional lesson plan template was replaced with the UDL lesson plan template. The UDL lesson plan consisted of general demographic information, lesson description, state standards, lesson goals, objectives, assessment (i.e., formative/ ongoing; summative/end of lesson assessment), variability of students, anticipatory set, introduction of new knowledge, guided practice, independent practice, and materials. Additionally, during the reflective process, TCs were asked to compare the quality of their teaching in this lesson to the first traditional lesson they implemented.

\section{Design and Data Analysis}

The research design was a concurrent triangulation mixed-method design (Creswell et al., 2003). Quantitative data included rubric ratings of the traditional and UDL lesson plans using an enhanced rubric from the EFE office. Researchers used a qualitative content analysis (Zhang \& Wildemuth, 2009) to condense data into categories or themes using inference and interpretation of completed lesson plan narratives (traditional and UDL), lesson videos, and lesson reflection narratives.

\section{Lesson Plans}

Lesson plans were scored with an enhanced EFE rubric consisting of 19 categories that were scored on a 4 -point Likert scale (i.e., $1=$ unacceptable, $2=$ marginal, $3=$ mastery, and $4=$ exemplary). While criteria were defined for the existing instrument, researchers added specific UDL measures examining variability, the nine UDL guidelines, and whether assessments were tied to an objective. Using the enhanced EFE rubric, researchers independently coded four TC lesson plans for both the traditional and the UDL lesson. Each researcher wrote anecdotal notes while scoring the lesson plans for each category and placed those notes in an independent table. Researchers then traded and independently coded the remaining four TC lesson plans completing their independent tables with narrative text. Researchers entered scores into a shared excel file and then determined interrater reliability using a point-by-point analysis of each score. A discrepancy range of $\geq 2$ points required a discussion between raters until agreement was reached. Initial interrater reliability for the traditional lesson plans was $100 \%$ with no 2 -point discrepancies. Initial interrater reliability for the 
UDL lesson plans was $98 \%$ with two discrepancies of 2 points, triggering a discussion and rubric adjustment for those two criteria. Scores displayed in Table 3 reflect the final total scores on lesson planning.

Table 3. Total Enhanced Education Field Experience Rubric Scores of Lesson Plans: Criteria and Universal Design for Learning (UDL) Guidelines

\begin{tabular}{lccc}
\hline & \multicolumn{2}{c}{ Lesson Plan } & \\
\cline { 2 - 3 } Participant ID & Traditional & UDL & Difference \\
\hline TC3 & 43 & 44 & +1 \\
TC6 & 43.5 & 51 & +7.5 \\
TC7 & 40 & 39 & -1 \\
TC10 & 53.5 & 41.5 & -12 \\
TC14 & 42 & 50 & +8 \\
TC15 & 38 & 34.5 & -3.5 \\
TC16 & 48 & 42 & -6 \\
TC17 & 38 & 33 & -5 \\
\hline
\end{tabular}

Note. $\mathrm{TC}=$ teacher candidate.

\section{Videos}

Using the three UDL principles as categories, researchers independently coded four TC lesson videos for both the traditional and the UDL lesson. Each researcher wrote anecdotal notes while watching the videos for each category and placed those notes in an independent table. Researchers then traded and independently coded the remaining four videos completing their independent tables with narrative text. After all videos were coded, researchers compared tables to determine intercoder reliability, the degree they were able to independently evaluate each data source and assign the same codes to each category (Tinsley \& Weiss, 2000). Researchers recorded the number of disagreements per TC video and category (Lombard, Snyder-Duch, \& Bracken, 2002). Intercoder reliability was calculated on all videos and considered acceptable with more than $80 \%$ (Neuendorf, 2002). Initial agreement for the representation and expression category was $87.5 \%$, and agreement for the engagement category was $81.25 \%$. Researchers then discussed findings and negotiated 100\% agreement (Garrison, Cleveland-Innes, \& Kappelman, J. 2006). Finally, researchers collapsed codes into emerging themes.

\section{Reflections}

Each researcher conducted an independent content analysis of four TC reflections for both the traditional and UDL lesson. Researchers sorted the text within the reflections by UDL principles. Researchers placed relevant text supporting each UDL principle in an independent table. Researchers then traded to code the remaining reflections to determine their inter-coder reliability rate (Tinsley \& Weiss, 2000) for each principle category was acceptable with more than $80 \%$ (Neuendorf, 2002). The calculated inter-coder reliability for each UDL principle was $93.75 \%$. Researchers negotiated agreement regarding the initial coding discrepancies (Campbell, Quincy, Osserman, \& Pedersen, 2013; Garrison et al., 2006) until they reached 100\% agreement. Finally, researchers further coded data into five categories and then collapsed the codes into three themes.

\section{In-Class}

As part of their typical assignment procedures, university supervisors used the In-Class rubric to observe and measure TCs throughout their first and second 8-week experiences. The In-Class rubric measures five standards (i.e., instruction planning, instruction delivery, learning environment, assessment, and communication) using 26 categories on a 4 -point Likert scale (i.e., $1=$ unacceptable, $2=$ marginal, $3=$ mastery, and $4=$ exemplary). The EFE office modeled the In-Class after the Mississippi Teacher Appraisal Instrument adopted by the Mississippi Department of Education. The 
instrument measures in-service teachers on the same five content standards. Researchers used the scores from the In-Class as an external measure of preservice teacher change.

\section{Results}

By comparing all sources of data, researchers hypothesized that TCs would plan more comprehensively after they were taught to use the UDL framework in their lesson planning. Researchers anticipated being able to observe significant positive changes in the UDL implementation videos. In addition, the researchers expected that TCs' reflections would demonstrate a deeper understanding of student variability and UDL principles and present an indepth reflection of how their teaching improved from their first half of student teaching to the second half. Findings from measures of TCs lesson plans, lesson videos, and lesson reflections are presented next. Researchers were able to confirm findings based on triangulation of these three data samples.

\section{Lesson Plans}

Researchers scored lesson plans using the EFE lesson planning rubric enhanced with additional measurement criteria focused on the nine guidelines of the UDL framework. Findings are presented in Table 3 and depict scored use of the UDL guidelines (increased use/decreased use) in traditional plans and UDL lesson plans. Overall, three out of the eight TCs exhibited an increase in their use of planned content falling under the UDL guidelines in their UDL lesson plan after the UDL seminar. Five of the eight TCs demonstrated a decrease in their use of planned content falling under the UDL guidelines in their UDL lesson plan score after the UDL seminar.

\section{Videos Observations}

Researchers first coded the video observations into the three UDL principles. Researchers independently noted what the TCs said and did, what they had students do, and what materials were used. Those notes were then sorted into the categories of representation, engagement, and action/expression. Table 4 depicts coded observation of the increased or decreased use of UDL principles in the traditional video and UDL video. Researchers defined emergent themes for each UDL principle.

\section{Representation}

Recurring themes emerged from the within the category of the UDL principle of multiple means of representation demonstrating how TCs represented content. TCs used (a) readily available technology; (b) novel objects, props, and manipulatives; and (c) multiple visual supports. During the UDL lesson, six of the eight TCs were observed, providing multiple visual supports during instruction. In the traditional lesson, three TCs used readily available technology, whereas four TCs made use of it during the UDL lesson, demonstrating growth of application in one TC. Researchers observed the most growth in TCs using novel objects, props, and manipulatives. In the traditional lesson, one TC used this type of representation; this grew to four TCs in the UDL lesson implementation. Researchers observed no change in the use of multiple visual supports during the lesson implementation. 
Table 4. Total Number of Teacher Candidates Coded as Demonstrating the Emerging Themes in Lesson Videos

\begin{tabular}{|c|c|c|c|}
\hline \multirow[b]{2}{*}{ Category/Theme } & \multicolumn{2}{|c|}{ Observed Lesson } & \multirow[b]{2}{*}{ Change } \\
\hline & Traditional & UDL & \\
\hline \multicolumn{4}{|l|}{ Representation } \\
\hline Readily available technology & 3 & 4 & +1 \\
\hline Novel objects, props, and manipulatives & 1 & 4 & +3 \\
\hline Multiple visual supports & 6 & 6 & 0 \\
\hline \multicolumn{4}{|l|}{ Action and expression } \\
\hline Multiple expression options & 3 & 5 & +2 \\
\hline Student use of technology & 0 & 1 & +1 \\
\hline Question-and-answer discussion & 8 & 8 & 0 \\
\hline \multicolumn{4}{|l|}{ Engagement } \\
\hline Multiple engagement options & 1 & 3 & +2 \\
\hline Verbal attention getters/behavioral & 0 & 3 & +3 \\
\hline \multicolumn{4}{|l|}{ Prompts } \\
\hline Partner or small-group instruction & 2 & 3 & +1 \\
\hline
\end{tabular}

Note. UDL = universal design for learning.

\section{Action and Expression}

Emerging themes from the UDL principle of multiple means of action and expression were TC use of (a) multiple expression options, (b) student use of technology, and (c) question and answer discussion. In the traditional lesson, three TCs used multiple expression options for students to demonstrate their knowledge, and five TCs used this theme in their UDL plan, showing an improvement in this application of two. During the traditional lesson, no TC provided any technology related option for their students to show what they had learned. However, one TC provided a technology option for their students' action and expression during the UDL lesson in the form of a learning management system software. All eight TCs relied on a question and answer discussion format for gauging their students' understanding in both the traditional and UDL lesson plan, so no change was observed in this theme.

\section{Engagement}

Emerging themes from the UDL principle of multiple means of engagement were the use of (a) multiple engagement options, (b) verbal attention getters or behavioral prompts, and (c) partner or small-group instruction. In the traditional lesson, one TC provided multiple engagement options for students, whereas in the UDL lesson, this grew to three TCs. During the traditional lesson, no TC used multiple verbal attention getters or behavioral prompts, whereas within their implemented UDL lesson three TCs were observed using them. TCs used a partner or small-group instruction format in their traditional lesson implementation which improved to three TCs using partner and small-group instruction in the UDL lesson implementation.

\section{In-Class Comparisons}

The In-Class Evaluation has 26 items with a maximum score of 104 (rubric available upon request). Results of the In-Class observation scoring conducted by university supervisors showed the following (see Table 5). Of the eight TCs, TC3 demonstrated a perfect score on both experiences, so no change was noted. TC16 also noted no change between first and second experiences. Whereas three TCs noted growth of 2 to 5 points, three other TCs noted declines of 1 to 4 points. 
Table 5. External Measure: University Supervisors' Total In-Class Rubric Scores

\begin{tabular}{lccc}
\hline & \multicolumn{2}{c}{ 8-Week Observation } & \\
\cline { 2 - 3 } Participant ID & First & Second & Change \\
\hline TC3 & 104 & 104 & 0 \\
TC6 & 102 & 104 & 2 \\
TC7 & 102 & 98 & -4 \\
TC10 & 98 & 97 & -1 \\
TC14 & 102 & 104 & 2 \\
TC15 & 103 & 101 & -2 \\
TC16 & 94 & 94 & 0 \\
TC17 & 98 & 103 & 5 \\
\hline
\end{tabular}

Note. $\mathrm{TC}=$ teacher candidate.

\section{Lesson Reflections}

As part of their student teaching assignments, TCs completed a reflection of their selected lesson plan and video. TCs were required by EFE to use the In-Class observation form as a guide for reflection. The analysis resulted in three themes from the reflections. Each of these themes is defined below.

\section{Things We Say and Use to Teach}

This theme included descriptions of materials, methods, models, and classroom management tools. Overall, the majority of reflective statements sorted into this theme. Examples of TC statements comprising this theme are as follows:

Next, the students watched a video. I held up alphabet cards.

If the letter contained the /Ii/ sound, the students instructed me to put a check mark by the word, but if the word did not contain the /Ii/ sound the students should instruct me to put an $\mathrm{X}$ on the word.

I allowed the students to work Problems 5-10 with a partner.

The students have assigned spots on the carpet and are asked to sit in their seats that they are assigned. The teacher is positioned in a place that she can monitor what is going on with the students all around her.

\section{Ways We Think About Students}

This theme included TCs' evaluative statements regarding their students. This incorporated TCs' reflections on what their students were doing and/or how they were feeling, what their students should be doing, how their students were arranged based on TCs perceptions of learning needs, and reflective statements about their student differences. This theme was the second most populated with reflective statements.

I helped Groups 1 and 2. They are my low groups. They are still having problems with labeling. The students are put into groups by learning levels....

There were 14 students available for this remedial lesson on text structures. Four of them were at a level of higher understanding, while five students were below level on this lesson which left five students ranging in the middle. 
Mrs. Pitts and I discussed the talking chips were a hit. The students were collaborating wonderfully together. All the students were engaged in the discussion. Mrs. Pitts said, "I am going to get me some talking chips."

Throughout the video, students are not paying attention when I am in the front of the room. They are fidgeting in desks, and some are talking to neighbors. I need to figure out a way to make the environment exciting and inviting, so that the students will pay attention to me every day.

I learned that it is, literally, almost impossible to truly keep the attention of 27 9-/10-yearolds. ...there are many instances where students look bored, are off task, talking, or distracting others at their table.

\section{Ways We Think About Teaching}

This theme included statements TCs made that were based on self-evaluation. It included summative statements on what TCs thought they did as they were teaching as well as reflective statements suggesting what they, as teachers, should be doing. Finally, this category included results related to the process reflection and self-evaluation. This theme had the fewest number of reflective statements. Examples of TC statements supporting this theme are as follows:

I noticed that I should allow more students to answer the questions that I asked. I noticed that I would ask a question and allowing one or two students to answer and then I would answer my own question. Instead of giving the students the answer so quickly, I should first listen to several students' response in order to determine who understands and who does not understand.

While teaching, I did not hear the students, but after watching the video I was able to hear some of the students' conversations. I plan to make sure my directions are very clear and easy for the students to understand.

I noticed that I need to improve keeping all of the students engaged in the lesson, gathering their attention at the beginning of the lesson, ensuring that the students are doing what was asked, managing the students' behavior during center time, and relating the concept to different cultures.

I need to improve my prompt feedback to the students because the majority of my feedback includes a comment of "okay" or "very good," and I feel I need to be more specific with the feedback that I give the students. I could also word my feedback in a way that creates more student centered learning by providing opportunities for the students to develop deeper meaning responses. I also need to be more forthcoming with the expectations I have with the students. They need to know the level of performance I expect him to achieve and how they can achieve it.

While in the moment in front of the students, it is much harder to remember all of the things that were done wrong and need improvement.

I continue to build interpersonal skills to aid in my goal of becoming an effective teacher. Each day I continue to work on the communications I have with the students and fellow teachers. 


\section{Discussion}

The use of a professional development day to teach the core components of UDL to preservice teachers did not create a substantial overall change in the practice of planning and instruction. Contrary to previous studies (Courey et al., 2012; Spooner et al., 2007), analysis of lesson plans and coded observations all reflect a minor-to-no change in overall planning and practice. University supervisors' scoring of the In-Class Evaluation reflected less growth on UDL lesson observations than researchers' ratings and, in three of eight cases, noted a decline. Courey et al. and Spooner et al. increased the incorporation of UDL into lesson planning by delivering UDL content in a course format followed by immediate UDL lesson planning. The current study provided a professional development day of UDL training followed by several weeks of student teaching before a UDL lesson plan, video, and reflection were submitted. Had researchers measured the lesson planning activity completed at the end of the professional development day, a stronger UDL presence may have been identified. However, because the lesson planning measurement was taken 2 to 4 weeks later in authentic teaching environments, the same level of inclusion of the principles of UDL was not identified as it had been previous research. It may be that the time between the training and the lesson planning did not allow for maintenance of the content and skills practiced in the seminar. Implementing the UDL framework requires a shift in thinking about learner variability while planning goals, methods, materials, and assessments (Meo, 2008). Coaching may be a beneficial solution to create maintenance. Additionally, TCs were fully teaching all lessons in their assigned classroom at the time researchers asked for this sample. It may be that TCs find using the UDL framework difficult or time intensive when compared to traditional lesson planning, particularly when planning for authentic, real-time content delivery. Intentional planning to meet all learners' needs requires an investment of time and practice (Evans et al., 2010). Previous research does not provide clear answers regarding how much time and practice is optimal for efficient and effective implementation. Interviews of preservice TCs might offer additional answers to inform this issue. Preservice teachers may have benefitted from team- or grade-level planning as a support model. Previous research has identified collaborative planning by teachers as an effective support for UDL implementation (Israel et al., 2014; Lowrey, Hollingshead, Howery, \& Bishop, 2017). TCs had more detailed reminders of what to include in each section of the traditional lesson plan template (e.g., helpful hints). The UDL framework is complex and takes place within a flexible continuum (Basham \& Gardner, 2010). Creating a UDL template to include more detailed instructions may support improved use of the UDL framework. However, close examination is needed to determine how directed a template should be to support preservice teachers application of the UDL framework in lesson planning, all the while maintaining the fluidity and flexibility of the framework.

Professional development emphasizing the principles, guidelines, and checkpoints seemed to effect minor change in the use of novel objects, props, and manipulatives as well as the engagement themes identified of (a) multiple engagement options, (b) verbal attention getters or behavioral prompts, and (c) partner or small-group instruction. However, researchers noted no major change in how TCs planned for the variability of learners and identified barriers to the learning process overall. Lesson plans designed using the UDL template continued to reflect reliance on sorting students into high, average, and low groups and arranging instruction to coincide with those perceptions of ability. Few changes were identified in planning options for students to express what they had learned in ways different from traditional question-and-answer sessions and written responses. Researchers noted the fewest exemplars recorded for the principle of action and expression as compared to the principles of representation or engagement. Teachers have expressed difficulty planning for students to express their knowledge in nontraditional methods, especially given the attention to standardized testing (Lowrey et al., 2017). To address this principle, understanding the variability of student needs a well as barriers to learning posed by the curriculum and environment is necessary as a teacher considers different ways for students to show what they 
know. More work is needed to facilitate supporting preservice teachers to think differently about students' action and expression. Findings from Vitelli (2015) and Scott et al. (2017) support improvement of the implementation of the UDL framework by preservice teacher educators and cooperating teachers in order to impact the improvement of the implementation of preservice teachers. Intervention efforts may need to be directed towards preservice teacher educators, university supervisors, and cooperating teachers.

While not explicitly stated in the UDL principles, guidelines, and checkpoints, identification of barriers to instruction and variability of learners is a key component of planning for instruction using the UDL framework (Hall et al., 2012; Israel et al., 2014). Results demonstrated TCs did not significantly increase their attention to difference by incorporating more means of representation and expression for the students. Perhaps future UDL professional development should weight instruction more heavily on the concepts of learner variability and barriers to instruction rather than discussion on principles, guidelines, and checkpoints.

A larger number of TCs did show growth in their understanding of the need to engage all of their students. The number of TCs using multiple options for engagement, employing behavior prompts and attention getters, and using different group configurations for instruction improved in the UDL implementation phase. However, understanding that one maintains that engagement through multiple means of representation, action, and expression was missing. Preservice teacher programs should address engagement as a principle necessary from lesson start to finish (Hollingshead, Carnahan, Lowrey, \& Snyder, 2016).

Addressing engagement from start to finish in a lesson may be an issue of the naiveté of preservice teachers as minimal attempts at providing multiple means of content representation and multiple ways for students to respond was missing in both traditional and UDL phases. TCs do not have a lot of experience in real classrooms prior to their student teaching experiences. That being said, the UDL lesson took place in their second 8-week experience (after roughly 10-12 weeks of teaching). It seemed reasonable to expect that TCs would have recognized a need for more attention to learner variability and be better equipped to recognize barriers to their instruction after their first experience. In fact, that was not the result of this study. TCs need support to identify barriers to instruction and learner variability in practice in order to understand and apply multiple means of representation, action, and expression. Mentoring and coaching may, in fact, support that change. Researchers have identified that teachers may not be fully implementing the UDL framework (Rao et al., 2014; Vitelli, 2015). Mentoring during planning and coaching during implementation may be beneficial to ensure TCs move past the initial "hook" or motivational piece of introducing a lesson into sustaining engaging materials and providing ways for students to express what they know that directly align with identified barriers and learner variability (Evans et al., 2010; Meo, 2008). Cooperating teachers and university supervisors may not feel confident in their own knowledge and skills coaching UDL (Scott et al., 2017).

Finally, reflections on teaching (to include planning, implementation, and assessment) are only as good as the reflection template used and may reflect the completion of a task (e.g., reflection assignment) rather than a reflective teaching mindset. As part of their EFE assignments, TCs were required to use the In-Class Evaluation tool as a basis for their reflections. They were to selfevaluate using the components of that tool. Several findings were noted. Two TCs used language for their first and second reflection that was almost exactly the same. These nearly identical reflections were clearly more of an attempt at compliance than an attempt of reflective self-evaluation. Reflections often times were summaries of what they'd done along with a summative list of what they could do better. Learning self-evaluation is a skill (Lee, 2005). Course content in preservice teaching should facilitate in-depth self-evaluation and reflection that moves beyond surface summaries of strengths and challenges. TCs did not provide reflections tied to any course content. 
No candidate mentioned any concept or content learned from any of their coursework. Also, TCs only named a few strategies (think-pair-share, choral reading, graphic organizers) in lesson plans or reflections. Facilitating a connection between course content and applied teaching experiences is critical for TC to connect research to practice. Preservice teacher programs should facilitate the use of evidence-based practices in authentic teaching experiences through coaching and directed reflections (Israel et al., 2014).

Although the impact of professional development geared around UDL planning and implementation seemed to be small, some overall growth was noted, specifically in the reflective statements made:

This lesson was designed specifically for a UDL evaluation, so there were elements I included that I had not done before. Seeing the students get excited because they were in control of which center they wanted to complete and who they wanted to work with was well worth the extra steps to include those options. I was surprised to see that the majority of my emergent learners chose the center that allowed them to give oral responses rather than writing. This was an excellent teachable moment because I was at this center, and I could spend the extra time with the learners that really needed the remediation. They diversified themselves without even knowing it.

I researched UDL and the conclusion I drew involved that I needed to find a way to have every single student interested. I racked my brain and knew that with all of the different learners in my room this was going to be a challenge. Within my classroom, I have a student ....and his IEP states that we are required to give him technology breaks throughout the day so he can regain focus. The stipulation of this student's IEP states that the student must not be forced into joining the rest of the class, but do it because he wants to and is interested. During my lesson using the UDL principle, I did not force my student to come to the carpet and he sat off practicing his punctuation skills on an iPad at a table during the presentation of the lesson on the carpet. After getting through my lesson and beginning my closure, he found an interest in what we were doing! I was so excited I wanted to scream! Everything I was trying to prove with the UDL principles was happening right before my eyes. All of a sudden, right when my students and I were about to start reading using the instruments, he trotted over to me and asked if he could join. He loves playing the drums, so when he saw out of the corner of his eye that he could play a drum, he immediately joined the rest of the class. I was so excited at this moment during my lesson it felt like my strongest moment throughout the whole lesson. I had to accommodate my student by his needs, which was done and then all of a sudden, I found him wanting to join my lesson because he was so intrigued!

\section{Limitations}

This investigation had several limitations. First, it was a preliminary effort with a small sample size. As such, those interested in this research should interpret these modest findings with caution. Additionally, while UDL was the focus, multiple variables beyond the control of researchers may have impacted the results. For example, although a new placement, TCs were more experienced in their second 8-week placement and may have been more adept at planning and presenting lessons. However, since results did not support substantial growth based on the implementation of UDL, increased experience did not seem to support UDL growth. There is also a possibility that the requirement for all to adhere to traditional lesson planning in their first experience and UDL lesson planning in their second experience may have created a possibility of order effects. A better design would be alternate the order for participants. Another limitation was that the videos analyzed were brief snippets of teaching rather than a full observation of candidates' actual teaching practice. Onsite observations may have supplied more holistic data of TC's teaching performance. The planning template provided for the construction of the lesson plans may have limited student 
teacher's conceptualization and ease of planning thereby affecting their overall lesson plan data. Finally, the incorporation of the introductory session at the beginning of student teacher may have indirectly impacted TCs' thinking and inclusion of UDL even in their first 8-week experience. Even so, due to the dearth of research in the area of UDL, these findings may inform future research efforts.

\section{Implications for Future Research}

The results of this study indicated the need for additional research examining the application of the UDL framework in preservice teacher planning and delivery of instruction. Future research should develop a larger scale study to determine whether or not the results of this small study are generalizable to a larger set of participants. A larger study will determine if the minimal change noted was specific to these participants or is representative of a larger group of TCs. Specific studies exploring ways to support TC to identify and address learner variability and barriers to instruction are needed. Studies exploring the role of mentors and coaches for TC as they learn to implement the UDL framework are needed. Mentoring and coaching could be examined from the role of university supervisors and/or cooperating teachers. Additionally, a study facilitating self-evaluation and reflective practices in TCs to encourage the linking of content to application as well as reflective thought that moves past summaries, strengths, and challenges is necessary to promote growth. This study demonstrated that teachers may not maintain their UDL training past a few weeks. Longitudinal studies are needed to determine if teachers use the principles, guidelines, and checkpoints into their first and continuing years of teaching.

\section{Conclusion}

This study evaluated the application of the UDL framework by eight TCs. TCs completed two phases of student teaching experiences: one traditional and one after receiving UDL professional development. Researchers analyzed two sets of data (i.e., lesson plan, video exemplar, reflection, and university supervisor evaluations) in both phases. Findings from this study did not support previous findings that minimal UDL instruction would impact lesson planning. More study is needed to identify ways to support preservice teacher education to implement the UDL framework in practice.

\section{References}

Allday, R. A., Neilsen-Gatti, S., \& Hudson, T. M. (2013). Preparation for inclusion in teacher education pre-service curricula. Teacher Education and Special Education, 36, 298-311. doi:10.1177/0888406413497485

Basham, J. D., \& Gardner, J. E. (2010). Measuring universal design for learning. Special Education Technology Practice, 12, 15-19.

Browder, D., Mims, P., Spooner, F., Ahlgrim-Delzell, L., \& Lee, A. (2009). Teaching elementary students with multiple disabilities to participate in shared stories. Research and Practice for Persons with Severe Disabilities, 33, 3-12. doi:10.2511/rpsd.331-2.3

Campbell, J. L., Quincy, C., Osserman, J., \& Pedersen, O. K. (2013). Coding in-depth semistructured interviews: Problems of unitization and intercoder reliability and agreement. Sociological Methods \& Research, 42, 294-320.

Center for Applied Special Technology (CAST). (2011). Universal design for learning guidelines Version 2.0. Wakefield, MA: Author.

Courey, S. J., Tappe, P., Siker, J., \& LePage, P. (2013). Improved lesson planning with universal design for learning (UDL). Teacher Education and Special Education, 36, 7-27.

doi:10.1177/088840641244617 
Coyne, P., Pisha, B., Dalton, B., Zeph, L. A., \& Smith, N. C. (2012). Literacy by design: A universal design for learning approach for students with significant intellectual disabilities. Remedial and Special Education, 33, 162-172. doi:10.1177/0741932510381651

Creswell, J. W., \& Garrett, A. L. (2008). The "movement" of mixed methods research and the role of educators. South African Journal of Education, 28, 321-333.

Creswell, J. W., Plano Clark, V. L., Gutmann, M., \& Hanson, W. (2003). Advanced mixed methods research designs. In A. Tashakkori \& C. Teddlie (Eds.), Handbook of mixed methods in social and behavioral research (pp. 209-240). Thousand Oaks, CA: Sage

Dymond, S. K., Renzaglia, A., Rosenstein, A., Chun, E. J., Banks, R. A., Niswander, V., \& Gilson, C. L. (2006). Using a participatory action research approach to create a universally designed inclusive high school science course: A case study. Research and Practice for Persons with Severe Disabilities, 31, 293-308. doi:10.1177/154079690603100403

Evans, C., Williams, J. B., King, L., \& Metcalf, D. (2010). Modeling, guided instruction, and application of UDL in a rural special education teacher preparation program. Rural Special Education Quarterly, 29, 41-48.

Every Student Succeeds Act, S. 1177, 114th Cong. (2015). Retrieved from https://www.govtrack.us/congress/bills/114/s1177

Garrison, D. R. M., Cleveland-Innes, M. K., \& Kappelman, J. (2006). Revisiting methodological issues in transcript analysis: Negotiated coding and reliability. Internet and Higher Education, 9, 1-8.

Hall, T. E., Meyer, A., \& Rose, D. H. (Eds.). (2012). Universal design for learning in the classroom: Practical applications. New York, NY: Guilford Press.

Higher Education Opportunity Act, H.R. 4137, 110th Cong. (2008). Retrieved from https://www.govtrack.us/congress/bills/110/hr4137

Holdheide, L. R., \& Reschly, D. J. (2008). Teacher preparation to deliver inclusive services to students with disabilities: TQ connection issue paper. Washington, DC: National Comprehensive Center for Teacher Quality.

Hollingshead, A., Carnahan, C., Lowrey, K. A., \& Snyder, K. (2017). Engagement for students with severe intellectual disability: The need for a common definition in inclusive education. Inclusion, 5, 1-15. doi.10.1352/2326-6988-5.1.1

Israel, M., Ribuffo, C., \& Smith, S. (2014). Universal design for learning innovation configuration: Recommendations for teacher preparation and professional development (Document No. IC7). Gainesville, FL: University of Florida, Collaboration for Effective Educator, Development, Accountability, and Reform Center. Retrieved from http://ceedar.education.ufl.edu/tools/innovation-configurations.

Kortering, L. J., McClannon, T. W., \& Baziel, P. M. (2008). Universal design for learning: A look at what algebra and biology students with and without high incidence conditions are saying. Remedial and Special Education, 29, 352-363. doi:10.1177/0741932507314020

Lee, H. J. (2005). Understanding and assessing pre-service teachers' reflective thinking. Teaching and Teacher Education, 21, 699-715.

Lieber, J., Horn, E., Palmer, S., \& Fleming, K. (2008). Access to the general education curriculum for preschoolers with disabilities: Children's school success. Exceptionality, 16, 18-32.

doi:10.1080/09362830701796776 
Lombard, M., Snyder-Duch, J., \& Bracken, C. C. (2002). Content analysis in mass communication: Assessment and reporting of intercoder reliability. Human Communication Research, 28, 587-604.

Lowrey, K. A., Hollingshead, A., Howery, K. \& Bishop, J. B. (2017). More than one way: Stories of UDL, inclusive classrooms, and students with ID. Research and Practice for Persons With Severe Disabilities, 42, 225-242. doi:10.1177/1540796917711668

Marino, M., Sameshima, P., \& Beecher, C. (2009). Enhancing TPACK with assistive technology: Promoting inclusive practices in pre-service teacher education. Contemporary Issues in Technology and Teacher Education, 9, 186-207.

Meo, G. (2008). Curriculum planning for all learners: Applying universal design for learning (UDL) to a high school reading comprehension program. Preventing School Failure: Alternative Education for Children and Youth, 52, 21-30.

Neuendorf, K. A. (2002). The content analysis guidebook. Thousand Oaks, CA: Sage.

Nye, B., Konstantopoulos, S., \& Hedges, L. V. (2004). How large are teacher effects? Educational Evaluation and Policy Analysis, 26, 237-257.

Organization for Economic Cooperation and Development. (2005). OECD annual report 2005. Retrieved from http://www.oecd.org/newsroom/34711139.pdf

Rao, K., Ok, M. W., \& Bryant, B. R. (2014). A review of research on universal design educational models. Remedial and Special Education, 35, 153-166. doi:10.1177/0741932513518980

Rose, D. H., \& Meyer, A. (2002). Teaching every student in the digital age: Universal design for learning. Alexandria, VA: Association for Supervision and Curriculum Development.

Sailor, W. S., \& McCart, A. B. (2014). Stars in alignment. Research and Practice for Persons with Severe Disabilities, 39, 55-64, doi:10.1177/1540796914534622

Scott, L. A., Thoma, C. A., Puglia, L., Temple, P., \& d'Aguilar, A. (2017). Implementing a UDL framework: A study of current personnel preparation practices. Intellectual and Developmental Disabilities, 55, 25-36.

Spooner, F., Baker, J. N., Harris, A. A., Ahlgrim-Delzell, L., \& Browder, D. M. (2007). Effects of training in universal design for learning on lesson plan development. Remedial and Special Education, 28, 108-116, doi:10.1177/07419325070280020101

Tinsley, H. E. A., \& Weiss, D. J. (2000). Interrater reliability and agreement. In H. E. A. Tinsley \& S. D. Brown (Eds.), Handbook of applied multivariate statistics and mathematical modeling (pp. 95-124). San Diego, CA: Academic Press.

Universal Design for Learning-Implementation and Research Network. (2011) Critical elements of UDL in instruction (Version 1.2). Lawrence, KS: Author. Retrieved from https://udlirn.org/wp-content/uploads/2018/01/Critical-Elements.pdf

U.S. Department of Education, Office of Educational Technology. (2016). Future ready learning: Reimagining the role of technology in education: 2016 National Education Technology Plan. Retrieved from https://files.eric.ed.gov/fulltext/ED571884.pdf

Van Laarhoven, T., Munk, D.D., Chandler, L.K., Zurita, L., \& Lynch, L. (2012). Integrating assistive technology into teacher education programs: Trials, tribulations, and lessons learned. Assistive Technology Outcomes and Benefits, 8, 32-47.

Vitelli, E. M. (2015). Universal design for learning: Are we teaching it to pre-service general education teachers? Journal of Special Education Technology, 30, 166-178. doi:10.1177/0162643415618931 
Waitoller, F. R., \& Artiles, A. J. (2013). A decade of professional development research for inclusive education a critical review and notes for a research program. Review of Educational Research, 83, 319-356. doi:10.3102/0034654313483905

Zhang, Y., \& Wildemuth, B. M. (2009). Unstructured interviews. In B. Wildemuth (Ed.), Applications of social research methods to questions in information and library science (pp. 222-231). Westport, CT: Libraries Unlimited.

[Appendices follow] 


\section{Appendix A}

\section{Traditional Lesson Plan Template}

\begin{tabular}{llll}
\hline Name: & Date: & School: & Grade Level: \\
Content Areas: & Lesson Topic: & & Period/Time:
\end{tabular}

Standards (CAEP 1.4) (InTASC 4)

Provide the College and Career Readiness Standards, (state) Framework Standards, and/or National Standards (e.g., ISTE, InTASK, discipline); include reference numbers. Please insure that all standards correlate with learning objective.

Learning Objectives (CAEP 1.1, 1.3) (InTASC 2)

List specific statements telling what the students will be able to do or will know at the conclusion of this lesson.

Assessment (CAEP 1.2) (InTASC 6)

How you will assess the children/students' achievement of the learner objectives? Describe the assessment that you will use to determine if the children/students met the lesson objectives. Some examples of lesson assessments include: observations, question/answer session, analysis of small group work, analysis of performance on specific work page, writing assignment. Attach a copy of any rubric or scoring key needed.

Differentiation/Accommodations (CAEP 1.1)

Explicitly explain how you will meet the needs of all of the students in the classroom: academic (highly proficient, struggling learners, ELL, etc.,), behavioral, and social; List the first names of students involved in each group.

\section{Procedures}

Anticipatory Set (InTASC 2, 7)

Introduce the lesson in meaningful way to engage, motivate, and capture children/students' attention; activate prior knowledge, connect to future content, and relate content to children/students' lives; Set behavioral expectations for the lesson's activities such as group work, whole class discussion, etc. 
Instructional Procedures (CAEP 1.1, 1.3, 1.4) (InTASC 1, 7, 8)

Include a numbered or bulleted list outlining how you will instruct this lesson from beginning to the end and how learner participation will be required

Instructional Strategies (CAEP 1.1, 1.3, 1.4, 1.5) (InTASC 2, 3, 4, 5, 8)

At the end of each activity/ instructional procedure, list what is provided to assist your visual, auditory, and kinesthetic learners; Label the teaching strategies used (whole group, small group, peer tutoring, independent, lecture, interactive technology, manipulatives, discussion, questioning, review, etc.,) for each activity

Closure (CAEP 1.1)

List closing statements, questions, or activity allowing students to express that they have achieved understanding of the lesson's main concepts

Materials (ISTE 2a)

List all materials needed for the teacher and the students; include page numbers, handout titles, worksheet titles, PowerPoint or Flip Chart titles, etc. 


\section{Appendix B}

\section{CAST's UDL Lesson Builder Template}

\begin{tabular}{l}
\hline About This Lesson \\
\hline Description \\
\hline Prerequisite \\
\hline Estimated Time \\
\hline Potential Use \\
\hline Purpose \\
\hline Grade \\
\hline Common Core \\
\hline Goals \\
\hline Instructional Goals \\
\hline Objectives \\
\hline Variability \\
\hline Assessments \\
\hline Formative Assessments \\
\hline Summative Assessments \\
\hline Instructional Methods \\
\hline Opening \\
\hline During \\
\hline Closing \\
\hline Materials \\
\hline Materials \& Supplies \\
\hline
\end{tabular}

The Journal of Educational Research and Practice provides a forum for studies and dialogue that allows readers to better develop social change in the field of education and learning. Journal content may focus on educational issues of all ages and in all settings. It also presents peer-reviewed commentaries, book reviews, interviews of prominent individuals, and additional content. The objectives: We publish research and related content that examines current relevant educational issues and processes aimed at presenting readers with knowledge and showing how that knowledge can be used to impact social change in educational or learning environments. Additional content provides an opportunity for scholarly and professional dialogue regarding that content's usefulness in expanding the body of scholarly knowledge and increasing readers' effectiveness as educators. The journal also focuses on facilitating the activities of both researcher-practitioners and practitioner-researchers, providing optimal opportunities for interdisciplinary and collaborative thought through blogging and other communications. Walden University Publishing: http://www.publishing.waldenu.edu 